\title{
An investigation into the efficient use of time in the calorimetric measurement of heat output
}

\author{
By A. B. CAIRNIE* and J. D. PULlaR \\ Rowett Research Institute, Bucksburn, Aberdeen \\ (Received 8 April 1959-Revised 9 Fuly 1959)
}

In many physiological investigations it is necessary to measure the energy metabolism of animals in a non-fasting state. Whereas the basal metabolic rate is at a steady level and can be measured by suitable methods during a few minutes while the requisite conditions persist, the total-energy metabolism is a function of many variables. Both the conditions at the time of the experiment and those previously pertaining may affect the measurement. The variables include factors with a $24 \mathrm{~h}$ periodicity such as muscular activity, feeding, light, ambient temperature and absorption of food, and secondly factors with other periodicities such as the sexual cycle, the cycle in the thickness of coat or fur, the season, and the phase of growth. The obvious way to avoid errors due to the effect of factors in the first group is to make measurements lasting $24 \mathrm{~h}$. The factors in the second group can normally be discounted on the grounds that their period is too long or their effect too small to influence the accuracy of such measurements.

Many different types of direct and indirect calorimeters suitable for the investigation of the total energy metabolism of animals over long periods have been described in the literature. The limitation of these instruments is not so much the difficulty and expense of construction but the time involved in making a single satisfactory measurement. It is therefore necessary to consider possible methods of increasing the output of accurate information per calorimeter, which might be accomplished in the various ways enumerated below.

(I) The diurnal cycle in the animals under experiment might be eliminated by the subjection of the animal to a non-periodic environment. Continuous food and continuous light were considered by Herring \& Brody (1938) to eliminate the diurnal cycle in rats after a week. If a similar effect were found in our experiments measurements in the calorimeter could be shortened.

(2) Measurements in the calorimeter might be carried out twice a day at the times when the diurnal cycle is in the region of its mean daily value.

(3) Correction might be made to the heat output measured for a short period at a particular time of day on the basis of knowledge of the form of the diurnal cycle.

(4) The length of the animal's 'day' might be made less than $24 \mathrm{~h}$. This 'day' could be adopted as the standard length of the period spent in the calorimeter.

* Present address: Department of Physiology, Marischal College, University of Aberdeen. 
These four possibilities have been investigated and their practicabilities assessed in experiments designed primarily to measure the effects of environmental temperature on the heat output of early-weaned piglets over the range of live weight 8-25 lb.

\section{EXPERIMENTAL}

Expt 1 . Three Large White $\times$ Wessex Saddleback male castrated litter-mate piglets were reared from 8 to $25 \mathrm{lb}$ weight in individual cages in a room by themselves. The temperature of the room was held constant at $20^{\circ}$. They were fed on a ration suitable for early-weaned piglets, diet I A of Smith \& Lucas (1957), with some changes in the mineral supplement, which contained, per lb: $\mathrm{FeSO}_{4} \cdot{ }_{7} \mathrm{H}_{2} \mathrm{O}$, I8.I g; $\mathrm{MgSO}_{4} \cdot{ }_{7} \mathrm{H}_{2} \mathrm{O}$, 22.9 g; $\mathrm{CuSO}_{4} \cdot{ }_{5} \mathrm{H}_{2} \mathrm{O}, 2.67 \mathrm{~g} ; \mathrm{MnSO}_{4} .4 \mathrm{H}_{2} \mathrm{O}, 7.40 \mathrm{~g} ; \mathrm{ZnSO}_{4} \cdot 7 \mathrm{H}_{2} \mathrm{O}, \mathrm{I} \cdot 97 \mathrm{~g} ; \mathrm{KIO}_{3}$, $0.076 \mathrm{~g} ; \mathrm{CoSO}_{4} .7 \mathrm{H}_{2} \mathrm{O}, 0.428 \mathrm{~g}$; maize starch, $200 \mathrm{~g}$; ground flaked maize, $200 \mathrm{~g}$. Food and water were available at all times. An electric light above each cage was always on. It was hoped that this regime would be sufficiently uniform to eradicate, or at least minimize, the diurnal cycle of heat output. Certain features of the regime were, however, regular each day. Although the piglets were reared in a partially sound-proofed room they were disturbed more frequently during working hours than at night. The cages and troughs were cleaned out at about $10.00 \mathrm{~h}$ every day, and it was unavoidable that the food supply was replenished at $23.00 \mathrm{~h}$ and not again until $09.00 \mathrm{~h}$. The animals nearly always ate a considerable amount of food when fresh water and meal were made available.

Twice a week each piglet spent a period of $2 \mathrm{I} \mathrm{h}$, beginning at $\mathrm{I} I . \mathrm{I}_{5} \mathrm{~h}$, alone in the calorimeter. The record for the ist hour of the run was always discarded. In the calorimeter the animal had room to move about. It received food and water as usual. The fresh food and water at the beginning of the run were again a stimulus to feeding. In so far as was possible the conditions simulated those to which the piglet was accustomed, though it had less light and could not see the other piglets. Extraneous noise would not penetrate to the animal.

Expt 2. Male castrated litter-mate piglets in a series of four groups, I, 2, 3 and 4, were reared in individual cages at constant temperatures of $15^{\circ}, 20^{\circ}, 25^{\circ}$ and $30^{\circ}$, respectively. Each group consisted of two pairs. The first pair was fed ad lib. every day from $09.00 \mathrm{~h}$ to $23.00 \mathrm{~h}$, when the food was removed. The only light was daylight. The other pair was kept in an enclosed compartment at the same temperature as the first pair, but with a constant intensity of electric light; the food supplies were replenished at I $1.00 \mathrm{~h}$ and $23.00 \mathrm{~h}$ each day. Until they were over $20 \mathrm{lb}$ weight the piglets were in effect fed ad lib. All piglets received water ad lib.

Each piglet spent a period of more than $24 \mathrm{~h}$ alone in the calorimeter once a week. The animals were put into the calorimeter alternately at $10.00 \mathrm{~h}$ and $22.00 \mathrm{~h}$, measurements being taken from $\mathrm{I} 1.00 \mathrm{~h}$ and $23.00 \mathrm{~h}$ onwards. Food and water were available in the calorimeter as usual. However, it was not possible to remove the food at $23.00 \mathrm{~h}$ if a run began at $\mathrm{II} .00 \mathrm{~h}$ with an animal from the first pair, since this would have involved the opening of the calorimeter and the loss of the record for the subsequent hour. In fact, the piglets ate little during the night. To maintain the symmetry of the 
design, some food was put into the trough when a run with a piglet from the first pair of a group began at $23.00 \mathrm{~h}$. Again, the conditions in the calorimeter simulated as closely as possible those in the cage-room.

Calorimetric methods. A gradient layer direct calorimeter, briefly described by Pullar (1957), was used. The electrical output of the calorimeter, proportional to the heat loss of the animal, was continuously recorded by a potentiometer. The records were integrated by planimeter for each hour of the run, the values for the Ist hour being discarded, and the hourly figures were then converted to rate of heat loss by means of known calibration values. The variations of the heat output could then be obtained for each run.

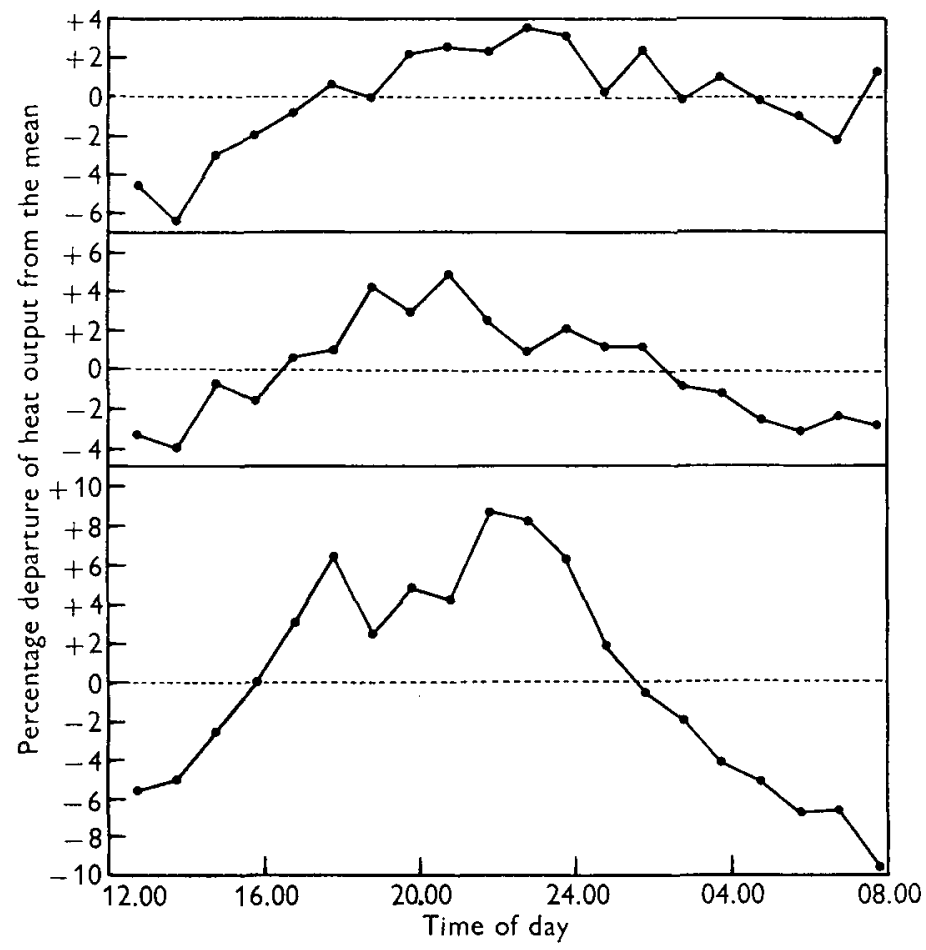

Fig. 1. Mean cycle of heat output for each of three piglets over the weight range $8-25 \mathrm{lb}$. The piglets were subjected to a regime without $24 \mathrm{~h}$ periodicity.

RESULTS

\section{Elimination of the diurnal cycle (Expt $\mathrm{I})$}

In so far as it was possible, though without extreme precautions, the piglets were subjected for more than 3 weeks to a regime which lacked a $24 \mathrm{~h}$ periodicity.

The mean cycle for the $20 \mathrm{~h}$ measurement is shown separately for each piglet in Fig. 1. These curves are the means of all measurements within the weight range $8-25$ lb. In Fig. 2 the mean cycle for all three piglets at weights $8-15 \mathrm{lb}$ is compared with the mean for weights $20-25 \mathrm{lb}$. The results show that the cycle did not diminish as the animals grew. 


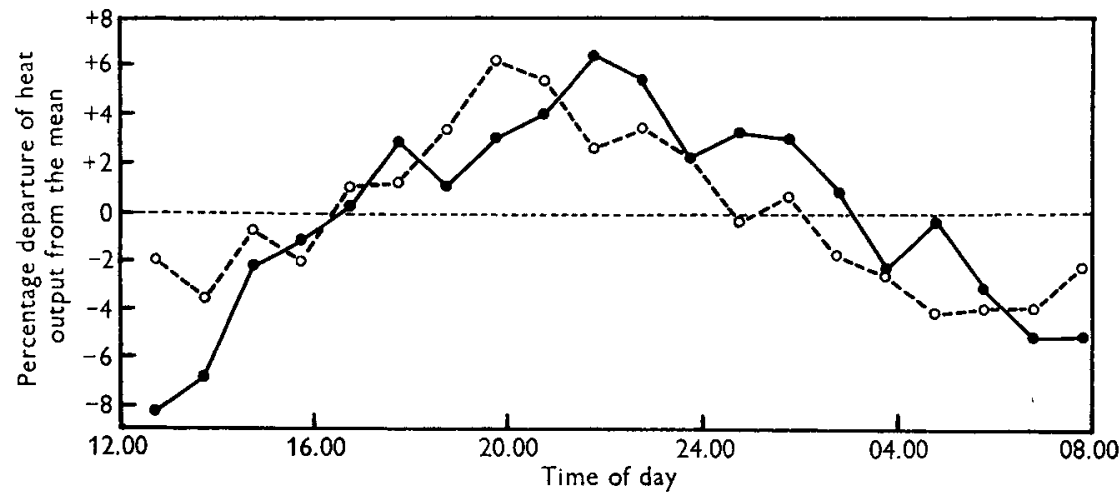

Fig. 2. Mean cycle of heat output for the three piglets of Fig. I subjected to a regime without $24 \mathrm{~h}$ periodicity. $0---\mathrm{O}$, weight range $8-15 \mathrm{lb} ; \bullet-\bullet$, weight range $20-25 \mathrm{lb}$.

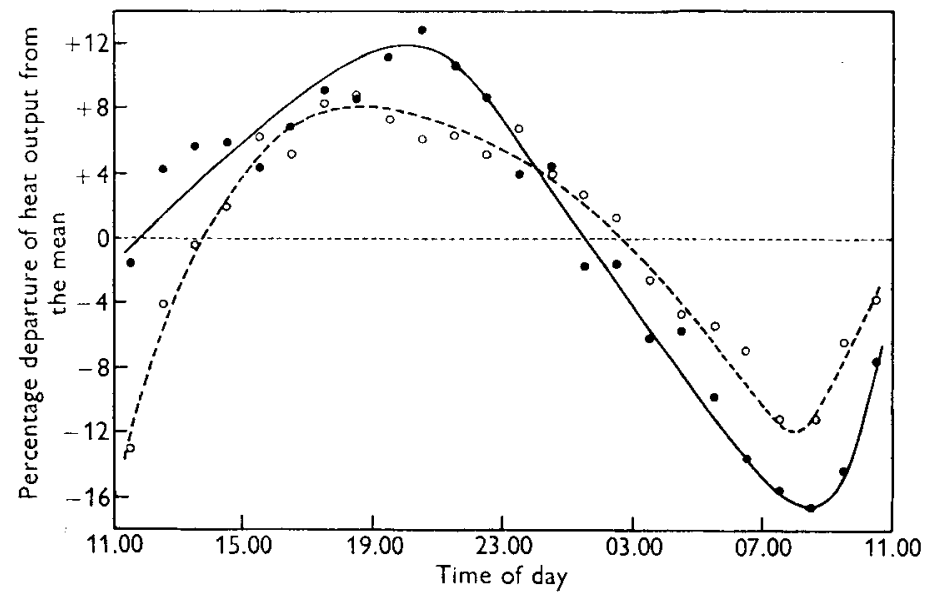

Fig. 3. Mean diurnal cycle for eight piglets subjected to a regime with $24 \mathrm{~h}$ periodicity. Weight range $8-25 \mathrm{lb}$.

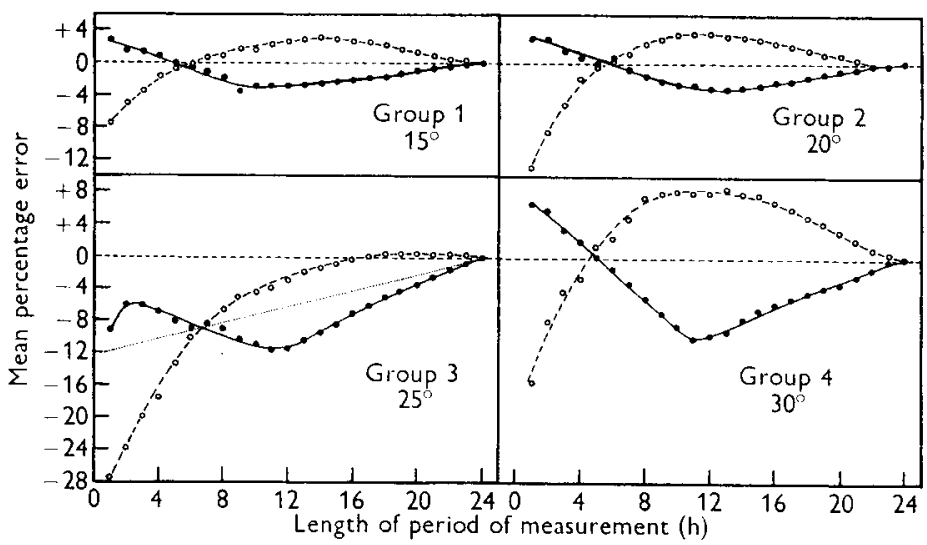

Fig. 4. Mean error introduced by assuming a run of given length beginning at $\mathrm{x} x .00 \mathrm{~h}$ or $23.00 \mathrm{~h}$ as typical of the whole day. $-\bullet$, runs beginning at $23.00 \mathrm{~h} ; 0-0$, runs beginning at I I.00 $\mathrm{h}$. The piglets were subjected to a regime with 24 h periodicity. For group 3 see also p. 438 . 


\section{Two short runs a day at chosen times (Expt 2)}

The mean diurnal cycle for the first pair of piglets of each group, eight animals in all, is shown in Fig. 3, from which a picture of the hour-to-hour variability can be obtained. The similarity between runs beginning at I I. $00 \mathrm{~h}$ and $23.00 \mathrm{~h}$ shows that the phase of the cycle depends on the time of day and not of the beginning of the run.

The total heat output from the beginning of the run to the end of the hour was measured, and from it the proportional total for $24 \mathrm{~h}$ was obtained for each hour of the runs. The difference between the proportional total and the actual total for $24 \mathrm{~h}$, expressed as a percentage of the latter, was then calculated. This percentage difference for the period up to the end of a particular hour of a run is a measure of the percentage error which would result if a measurement over this period beginning at $\mathrm{I} I .00 \mathrm{~h}$ or $23.00 \mathrm{~h}$ were considered typical of the whole day. The mean percentage errors of estimates, based on periods of from I to $24 \mathrm{~h}$, were then found for each group. In Fig. 4 the mean percentage error is plotted as a function of the length of the period of measurement for runs beginning at both times for all the groups. Group 3, kept at $25^{\circ}$, is considered later (p. 438 ).

It is clear from Fig. 4 that, on average, measurements over $5 \mathrm{~h}$ periods beginning at I $1.00 \mathrm{~h}$ or $23.00 \mathrm{~h}$ would give accurate estimates of the $24 \mathrm{~h}$ total. Reference to Fig. 3 explains this finding. In this experiment these periods straddle the mean value for the day. If the runs had begun earlier, estimates of similar accuracy would have required longer periods of measurement.

The mean percentage error for the first $5 \mathrm{~h}$ of all the runs, excluding group 3 , was $-0.3 \%$, but the standard deviation of the error was $5.0 \%$. For accurate calorimetric work a standard deviation of this magnitude is unacceptable.

\section{Correction of heat output according to time of day (Expt 2)}

If the variation of the percentage error about the mean were small, the heat output measured over any part of the day could be corrected on the basis of curves of the type shown in Fig. 4. The curves for group 2, kept at $20^{\circ}$, are repeated in Fig. 5, which shows also the values for the eight individual runs at this temperature from which the mean curves were obtained. The variation between runs was so large, and decreased so slowly as the length of the period of measurement was increased, that correction cannot be made with confidence on the basis of the mean error. The diurnal cycle is not sufficiently well regulated from day to day or from animal to animal for this method to be of value.

\section{Establishment of a $12 h$ 'day' (Expt 2)}

The second pair of piglets in each group lived under conditions of $\mathrm{I} 2 \mathrm{~h}$ periodicity and little $24 \mathrm{~h}$ periodicity. The length of their 'day' and the times of beginning of the measurements in the calorimeter, $11.00 \mathrm{~h}$ and $23.00 \mathrm{~h}$, were chosen for convenience.

The heat outputs during the two $\mathrm{I} 2 \mathrm{~h}$ periods of each run were calculated separately and are given in Table $\mathrm{r}$. Equal numbers of runs beginning at $\mathrm{Ir} .00 \mathrm{~h}$ and $23.00 \mathrm{~h}$ were used in the analysis to minimize the effect of growth during the runs. The mean differences for the groups were $+0 \cdot 4,-1 \cdot 7,+5 \cdot 8$ and $+0 \cdot 2$, respectively. Since the 
standard errors of the means, also given in Table $\mathbf{~}$, are large the mean difference is not significantly different from zero for any group.

It is clear that the variability between consecutive periods of $\mathrm{I} 2 \mathrm{~h}$ is too large to be neglected. In the calculation of the mean differences between the two $12 \mathrm{~h}$ periods the effects of growth as the run progressed were largely excluded. However, no such exclusion was possible in the calculation of the standard errors of the means. Since piglets grow very rapidly, an increase in weight of $10 \%$ in $24 \mathrm{~h}$ being common, the effects of growth cannot be neglected. The possibility remains that there may be a close correlation between the difference in mean weight and the difference in heat output for the two periods.

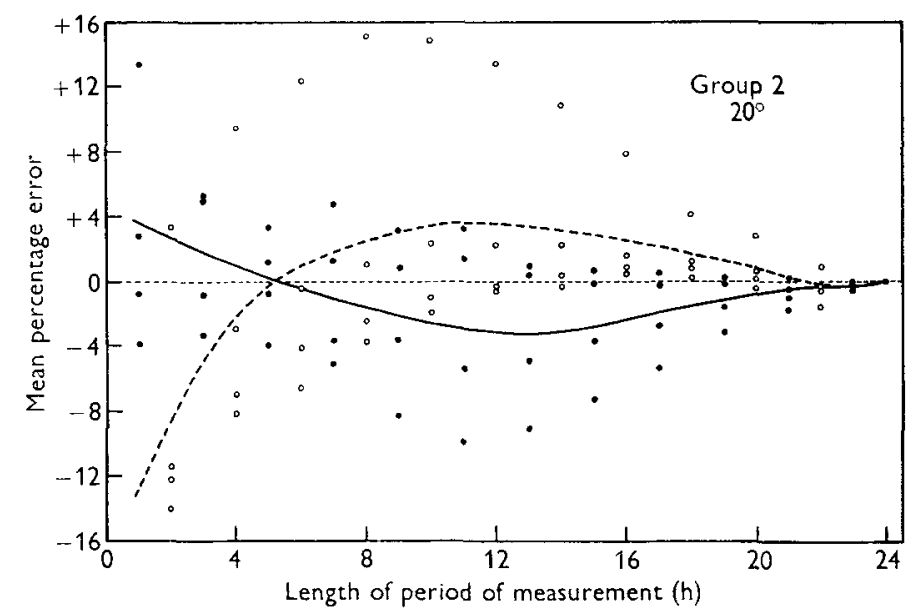

Fig. 5. Range of the error introduced by assuming a short run as typical of the whole day. The data are shown for alternate hours of the eight individual runs with piglets from group 2 (Fig. 4). $\bullet$, runs beginning at $23.00 \mathrm{~h} ; 0$, runs beginning at $\mathrm{I} \mathrm{I} .00 \mathrm{~h}$.

If the heat output is given by the relation

$$
Y=k W^{b}
$$

where $W$ is the body-weight and $k$ and $b$ are constants for a group, and $y$ is the change in heat output corresponding to a small change in weight $w$, then

$$
Y+y=k(W+w)^{b}=k W^{b}(\mathbf{r}+w / W)^{b} .
$$

Therefore $y / Y=b(w / W)$ as a first approximation. If $y / Y$ and $w / W$ are found to bear this relation to one another, the variability between the periods could be reduced by removing the effect due to change in mean weight.

The values of $y / Y$ and the estimated values of $w / W$ for all the runs are given in Table I. Unfortunately it was only possible to estimate $w / W$ because the animals were weighed only at the beginning and end of runs more than $24 \mathrm{~h}$ long. The assumption was made that the weight of the animals changed at a steady rate throughout the run. No correlation was found between percentage change in weight and heat output. 


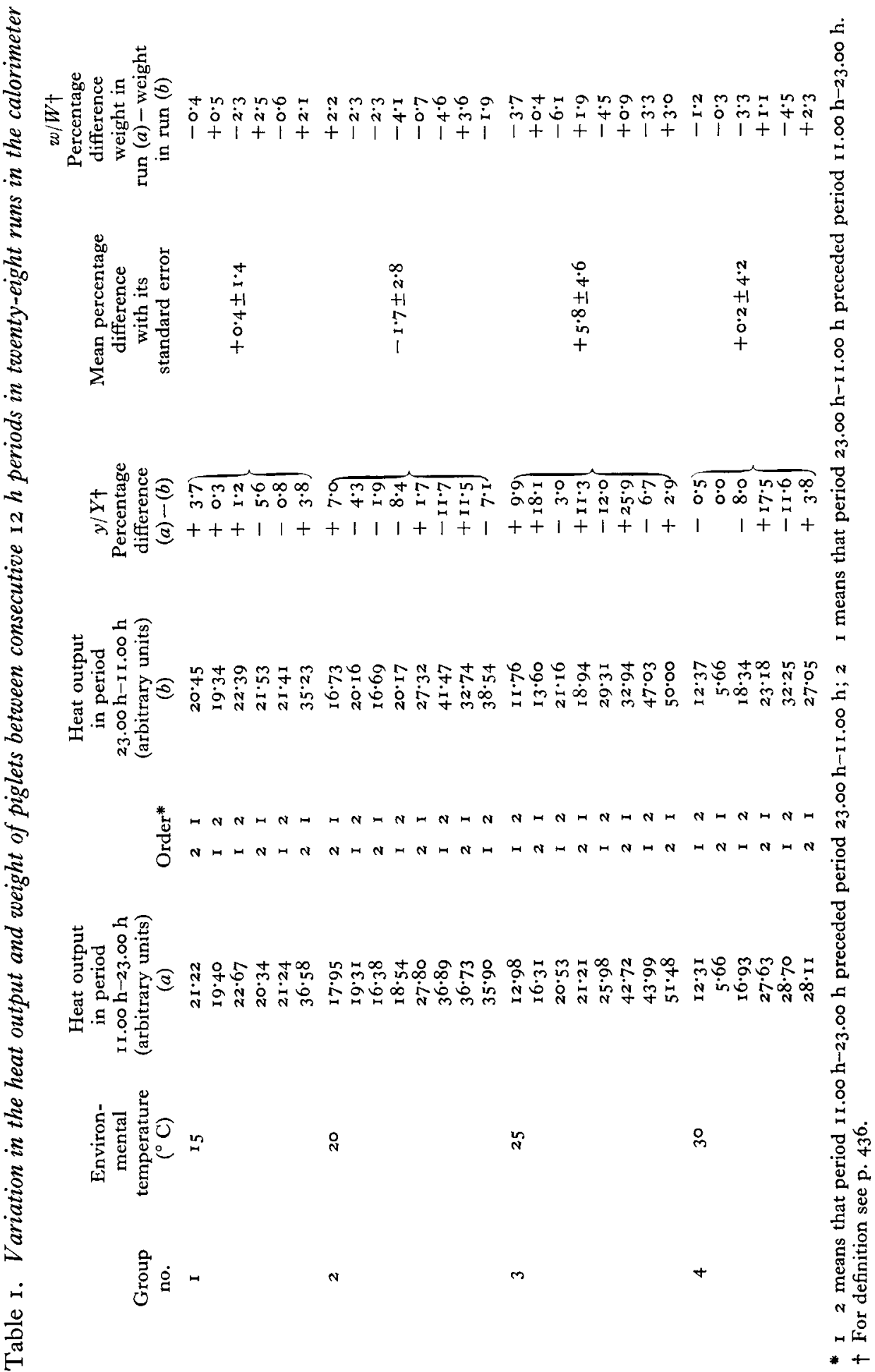




\section{DISCUSSION}

In the first three experimental approaches considered no account was taken of the growth that occurred in the course of a $24 \mathrm{~h}$ run, which with piglets would be not insignificant. In fact, the heat output does not vary about a steady level throughout the day, as it has been considered to do, but about a level which may rise appreciably in $24 \mathrm{~h}$. In Fig. 3 the diurnal cycles for runs beginning at $\mathrm{I} \mathrm{I} .00 \mathrm{~h}$ and $23.00 \mathrm{~h}$ cross at $23.00 \mathrm{~h}$. Between $\mathrm{II} .00 \mathrm{~h}$ and $23.00 \mathrm{~h}$ the heat output for the runs beginning at $23.00 \mathrm{~h}$ was slightly higher than that for runs beginning at $\mathrm{I} \mathrm{I} .00 \mathrm{~h}$, but after $23.00 \mathrm{~h}$ the heat output for runs beginning at $\mathrm{I} I .00 \mathrm{~h}$ was the higher. It is suggested that a large part of the difference between the two diurnal cycles is due to growth.

The piglets in group 3 were reared at $25^{\circ}$, which has been found to be the temperature for optimum growth of early-weaned piglets (A. B. Cairnie and J. D. Pullar, unpublished data). The heat output was in general considerably greater at the end of the runs than at the beginning. The effect of growth during $24 \mathrm{~h}$ could be neglected for groups $I, 2$ and 4 , but not for group 3 (Fig. 4). The effect can be eliminated in group 3 by taking as the abscissa in Fig. 4 the dotted line drawn through the intersections of the two curves. If this procedure is accepted, the curves are similar to those for groups I, 2 and 4 .

The biological variation in heat output encountered in some calorimetric experiments is surprisingly small. We found in one unpublished experiment with piglets that the within-animal coefficient of variation was $\mathrm{I} \cdot 6 \%$, and that the coefficient of variation between unrelated animals was only $2 \cdot 8 \%$. The absence of large biological variations makes it necessary therefore for the technique of calorimetry to attain a high order of accuracy. Instrumental errors below $\pm \mathrm{I} \%$ must certainly be the aim.

None of the procedures that might have increased the rate of collection of information in these experiments with piglets has been found to be justifiable since all would have seriously reduced the intrinsic accuracy of the apparatus in use. We found no alternative to the usual procedure of making measurements of the total energy metabolism over a period of $24 \mathrm{~h}$.

\section{SUMMARY}

I. The results of two experiments have been analysed to investigate possible methods of increasing the rate of collection of accurate information from direct calorimetry.

2. Three piglets were reared under a regime with little $24 \mathrm{~h}$ periodicity. After 3 weeks the $24 \mathrm{~h}$ cycle of heat output was not diminished.

3. Eight piglets were reared at constant temperatures under a regime with a rhythm of $24 \mathrm{~h}$ in light. The variability of the cycle of heat output about its mean was too great for assessment of the daily total from short-period measurements.

4. Eight piglets were reared under a regime with a $12 \mathrm{~h}$ periodicity. For any one animal the variability between the measurements of heat output during successive $\mathrm{I} 2 \mathrm{~h}$ 
periods was too great to be neglected, and could not be corrected on the basis of estimated change in body-weight.

5. No alternative has been found to the usual procedure of making measurements of the total energy metabolism over a period of $24 \mathrm{~h}$.

\section{REFERENCES}

Herring, V. V. \& Brody, S. (1938). Res. Bull. Mo. agric. Exp. Sta. no. 274.

Pullar, J. D. (1957). Advanc. Sci., Lond., 13, 49 I.

Smith, H. \& Lucas, I. A. M. (I957). F. agric. Sci. 49, 409.

\section{Experimental production of vitamin $B_{12}$ deficiency in rats and mice on a maize-groundnut-meal diet}

By PREMA FATTERPAKER, W. V. LAVATE, A. G. MULGAONKAR, J. M. NORONHA, D. V. REGE, H. P. TIPNIS AND A SREENIVASAN

\section{Department of Chemical Technology, University of Bombay, Matunga Road, Bombay}

(Received 10 April 1959-Revised 30 Fune 1959)

Difficulties in the production of vitamin $B_{12}$ deficiency in rats and mice are encountered, and can be attributed to the high maternal reserves of the vitamin in animals bred from normal mothers, as well as to intestinal synthesis. Iodinated casein, thyroid extract or thyroxine have been frequently used in purified diets to accelerate depletion of vitamin $\mathrm{B}_{12}$ reserves (see, for example, Ershoff, I947; Bosshardt, Paul, O'Doherty, Huff \& Barnes, r949; Nichol, Dietrich, Cravens \& Elvehjem, I949; Fatterpaker, Marfatia \& Sreenivasan, 1955). Alternatively, various types of all-vegetable diets, usually with a large proportion of soya, and sometimes with maize in addition, have been used (Rubin \& Bird, r947; Zucker \& Zucker, r950; Ling \& Chow, 1952; Register, I954; Ericson, Harper, Williams \& Elvehjem, 1956). A more severe deficiency can be induced if the animals are bred from mothers previously maintained on such diets. Specially reared animals of that type are used in some laboratories for routine biological assays of vitamin $\mathrm{B}_{12}$ (Zucker \& Zucker, I950; Bliss \& György, I95 I ; Jukes \& Williams, 1954).

There is a possibility that supplementation with iodinated protein or other thyroidactive material may not always cause uncomplicated vitamin $B_{12}$ deficiency, and the work described here was therefore undertaken to ascertain: (I) the effectiveness of an all-vegetable protein diet of maize-and-groundnut meal in producing vitamin $B_{12}$ deficiency in mice and rats; $(2)$ the nature and severity of the deficiency in comparison with that produced by incorporating iodinated casein in the same diet, and (3) the counteraction by dietary vitamin $\mathrm{B}_{12}$ of the deficiencies produced. 